\title{
School Nutrition Professionals' Employee Safety Experiences During the Onset of the COVID-19 Pandemic
}

\author{
Emily Vaterlaus Patten, PhD, RDN, CD ${ }^{1}$; Emma Beckstead, RDN, CD ${ }^{2}$; Mckenna Jones, $\mathrm{BS}^{1}$; \\ Lori Andersen Spruance, PhD, $\mathrm{CHES}^{2}$; Dayle Hayes, MS, RDN ${ }^{3}$
}

\begin{abstract}
Objective: To explore the real-time personal/employee safety experiences and perspectives of school nutrition professionals ranging from frontline staff to state leadership across the US as they responded to the initial weeks of the coronavirus pandemic.

Methods: A cross-sectional survey was administered electronically March 31-April 20, 2020, to school nutrition staff, managers, directors, and state agency personnel. Descriptive statistics were calculated, and a thematic analysis of an open-ended item was conducted.

Results: School nutrition professionals $(n=504)$ from 47 states responded. Most $(86.6 \%)$ reported that ensuring employee safety was somewhat or much more difficult during the pandemic, and they were unaware of an emergency plan. Themes from open-ended responses regarding employee safety concerns included, exposure and transmission risk, processes, and personal concerns.

Conclusions and Implications: Attention to the safety and concerns of school nutrition employees is vital for continuation of these programs during this pandemic and for future emergency situations.

Key Words: school nutrition, food insecurity, COVID-19 pandemic, child hunger, employee safety (J Nutr Educ Behav. 2021;53:2-9.)
\end{abstract}

Accepted October 29, 2020. Published online November 5, 2020.

\section{INTRODUCTION}

Under typical circumstances in 2019 , 4.8 billion school lunches and 2.4 billion school breakfasts were served to children through federally funded child nutrition programs. ${ }^{1}$ These programs facilitate the provision of nutritionally balanced meals to children and are offered for free or at reduced prices on the basis of household financial eligibility criteria $^{2}$; $74.1 \%$ of lunches and $85.1 \%$ of breakfasts were either free or reduced-price in $2019 .{ }^{1}$ Child nutrition programs such as these exist to improve food security for children, and research has indicated that these programs contribute to diet quality and academic performance for children in food-insecure or low-income households. ${ }^{3}$ Food insecurity in the US has declined somewhat since the 2007-2009 economic recession ended, however, food insecurity among households with children has persisted at higher than prerecession levels. ${ }^{3}$

In early March 2020, the coronavirus disease 2019 (COVID-19) outbreak began in the US. ${ }^{4}$ The pandemic has introduced challenges that complicate and possibly compound food security for children in the US. For example, many kindergarten-12th grade (K-12) schools closed their physical campuses in March, $2020^{5}$ thus eliminating immediate access to breakfast and/or lunch for many children. Furthermore, children whose households were previously food secure may have been negatively affected by the COVID-19 pandemic-

\footnotetext{
${ }^{1}$ Department of Nutrition, Dietetics, and Food Science, Brigham Young University, Provo, UT

${ }^{2}$ Department of Public Health, Brigham Young University, Provo, UT

${ }^{3}$ Nutrition for the Future, Inc, Billings, MT

Conflict of Interest Disclosure: The authors have not stated any conflicts of interest.

Address for correspondence: Emily Vaterlaus Patten, PhD, RDN, CD, Brigham Young University, S-231 ESC, Provo, UT 84604; E-mail: Emily_patten@byu.edu

(C) 2020 Society for Nutrition Education and Behavior. Published by Elsevier Inc. All rights reserved.

https://doi.org/10.1016/j.jneb.2020.10.021
}

related surge in US unemployment, which rose to $14.7 \%$ in April 2020, ${ }^{6}$ the highest rate since 1948. Experts have projected the number of foodinsecure children will total 12.4 -18 million owing to unemployment and increased poverty rates related to the COVID-19 pandemic.?

On March 9, 2020, the US Department of Agriculture's Food and Nutrition Service began issuing waivers allowing sponsors to use the Summer Food Service Program or the Seamless Summer Option of the National School Lunch Program to serve meals in noncongregant settings, ${ }^{8}$ and many school nutrition leaders ramped up the distribution of emergency meals to meet the nutrition needs of their communities' children. As of March $27,2020,82 \%$ of public schools were providing students with a meal service. $^{9}$ School nutrition programs have responded to other emergencies (eg, natural disasters) in the past, ${ }^{10,11}$ but the COVID-19 pandemic poses unique response challenges. One challenge is that social distancing mandates (individuals keeping $6 \mathrm{ft}$ apart from each other) increase the difficulty of employees producing and distributing meals safely. ${ }^{12}$ 
Another challenge is that COVID-19 is affecting the entire country instead of a relatively contained region. Despite past disasters, many states are not accustomed to and may not have been ready for an emergency feeding situation of this nature, leaving schools in many areas with limited state guidance. For example, research conducted with school nurses showed that only $8.3 \%$ of schools had a foodservice biosecurity plan. ${ }^{13}$

The success of mitigating child food insecurity through school nutrition programs lies with those who work for and manage them. During the pandemic, most states have deemed school nutrition employees essential ${ }^{14}$ as governments have recognized the need to feed students who would not eat without emergency meals. Paraphrasing a recently published Lancet article, essential workers must be protected to protect the well-being of everyone. ${ }^{15}$ Currently, little is known about the experience of school nutrition professionals and leaders outside of media sources. The media can distort the public's vision of leaders during crises, ${ }^{16}$ making it important to explore the experiences of school nutrition professionals and leaders directly. The purpose of this study was to explore the realtime personal/employee safety experiences and perspectives of school nutrition professionals ranging from frontline staff to state leadership across the US as they responded to the initial weeks of the coronavirus pandemic.

\section{METHODOLOGY}

\section{Survey Instrument}

A 55-item survey instrument with both closed- and open-ended items was developed to explore the experiences of a convenience sample of school nutrition professionals. This article focuses on the employee experience of school nutrition professionals including 2 items about emergency plans, 5 items exploring the frequency of employee safety protocol implementation, and an open-ended item about employee safety concerns ("What are your greatest safety concerns for employees/volunteers [including yourself]?"). Various characteristics of the respondents and their work situations were measured, such as their current role in school nutrition, the state and school districts they represented, if their position was deemed essential, and the length of time they had been providing emergency meals. Job satisfaction, ${ }^{17}$ work/ life balance, ${ }^{18,19}$ and burnout $^{20}$ were also assessed. Job satisfaction was measured on a 5-point Likert scale ranging from 1 (very satisfied) to 5 (very dissatisfied). ${ }^{17}$ Similarly, the respondents were asked to rate their work/life balance by responding to the statement, "Currently, the balance between my personal and professional commitments is about right" on a 5-point Likert scale ranging from strongly agree to strongly disagree. ${ }^{18,19}$ Burnout was measured on a 5-category ordinal scale with any response above a 2 ("Occasionally I am under stress, and I don't always have as much energy as I once did, but I don't feel burned out.") indicating some level of burnout. ${ }^{20}$ The instrument was expert-reviewed by school nutrition professionals $(n=3)$ and another school nutrition program researcher before distribution for content and functionality. Brigham Young University's Institutional Review Board approved this study before data collection.

The respondents were initially presented with an informed consent statement delineating the purpose of the study, the voluntary nature of participation, the potential risks and benefits of participation, researchers' identity and commitment to confidentiality, and that the survey would take approximately 15 minutes to complete. The respondents choosing to participate indicated their consent to participate by clicking yes. To maintain a logical flow, the order of survey questions was not randomized, but potential bias was limited owing to the objective nature of most questions (such as service type, job title, etc). None of the questions were mandatory.

\section{Data Collection}

The survey was open March 31-April 20, 2020. All state directors were emailed an invitation and link to the Web survey. The survey was also posted as a sharable link and Quick Response code on Facebook (Facebook, Inc, Menlo Park, CA) groups entitled "Tips for School Meals That
Rock," "Build Up Dietitians - School Nutrition," and the Institute of Child Nutrition's account. The target audience of these Facebook pages is school nutrition professionals, and these pages were selected because of their wide reach (at the time they had 13,779; 528; and 3,945 members, respectively). The survey announcement encouraged respondents to share the survey link with other school nutrition professionals. This sampling process was used because it was the most direct way to access this population under the circumstances; other research about the coronavirus pandemic has used social media for recruitment. ${ }^{21,22}$ Responses ultimately came through the anonymous shareable link $(\mathrm{n}=510)$, invitation over e-mail $(\mathrm{n}=17)$, and from the Quick Response code $(n=5) ; 30$ responses were excluded because the respondents did not advance past the initial item. The average completion time was 12.38 minutes. The respondents were not required to participate and were not offered incentives or compensation.

\section{Data Analysis}

Descriptive statistics were calculated using SAS software (version 9.4, SAS Institute Inc, Cary, NC, 2013). A qualitative thematic approach was used to analyze responses $(n=315)$ to an open-ended item that was: "What are your greatest safety concerns for employees/volunteers (including yourself)?" Two researchers with previous experience conducting qualitative analyses independently immersed themselves in the data by reading and rereading participant responses to begin brainstorming preliminary thematic coding categories. They then met to discuss their perceptions of the data and agreed on initial themes. Each theme was developed and defined in a code book, and then the researchers coded the data independently. ${ }^{23}$ Next, intercoder agreement was calculated by hand $(83 \%$; number of coding agreements divided by total number of codes). All coding discrepancies were discussed, and researchers consulted the data as needed to develop a final coded document. 


\section{RESULTS}

The final sample consisted of 504 respondents in a variety of roles ranging from state leadership to frontline school nutrition staff, with representation from 47 states (Alaska, Delaware, Hawaii, and Washington, DC were not represented). The most common role among the respondents was nutrition program director (42.9\%; Table 1). The respondents who selected a state-level role or other described their contribution to the pandemic response. State directors/personnel reported providing guidance for technical issues and new procedures/protocols, waiver submissions, application approvals, product procurement, and staff management. They communicated with the media and government officials and described themselves as leaders and advocates. Those who selfselected other as their role indicated a variety of responsibilities in supporting school nutrition during the COVID-19 response and were most commonly dietitians, consultants, menu managers, and bookkeepers/clerks. Only $21.9 \%$ of the respondents were aware of an emergency plan, and those who were aware of the plan ranged in how they rated the effectiveness of that plan (Table 1). Other characteristics of the sample are shown in Table 1.

Ten respondents stated they were not currently working to provide

Table 1. School Nutrition Foodservice Processes and Personal Experiences During Coronavirus Disease 2019 Pandemic Emergency Feeding Response $(n=504)$

\section{Variable}

Current role

State agency director

State agency personnel

Nutrition program director

Nutrition program manager

Nutrition program supervisor

Nutrition program staff

Other

Duration of providing meals

$<1$ wk

$1-2$ wks

3-4 wks

$>4$ wks

Service model(s)

Meal pickup at schools (curbside)

Delivery along bus routes

Pickup at other designated site

Home delivery

Meal pickup at schools (walk-in)

Other

Approach to meal service

One meal snack/at a time

One day's meals/snacks at a time

Multiple days' meals/snacks at a time

Other

Meals served during pandemic ${ }^{b}$

Breakfast

Lunch

Supper

Snack

Other (please specify)

Frequency of adequate staffing

Always

Most of the time

About half of the time

Sometimes

Never

\begin{tabular}{|c|c|c|}
\hline$n^{a}$ & $\%$ & Variable \\
\hline & & Previously aware of emergency plan \\
\hline 13 & 2.6 & Yes \\
\hline 9 & 1.8 & No \\
\hline 214 & 42.9 & Effectiveness of emergency plan \\
\hline 104 & 20.8 & Extremely effective \\
\hline 34 & 6.8 & Very effective \\
\hline 78 & 15.6 & Moderately effective \\
\hline 47 & 9.4 & $\begin{array}{l}\text { Slightly effective } \\
\text { Not effective at all }\end{array}$ \\
\hline 2 & 0.5 & Satisfaction with meal service \\
\hline 105 & 27.3 & Extremely satisfied \\
\hline 263 & 68.3 & Somewhat satisfied \\
\hline 15 & 3.9 & $\begin{array}{l}\text { Neither satisfied nor dissatisfied } \\
\text { Somewhat dissatisfied }\end{array}$ \\
\hline 326 & 62.5 & Extremely dissatisfied \\
\hline 125 & 32.5 & Student meal participation during school closures \\
\hline 116 & 30.1 & Significantly higher \\
\hline 97 & 25.2 & Slightly higher \\
\hline 68 & 17.7 & About the same \\
\hline 1 & 0.3 & $\begin{array}{l}\text { Slightly lower } \\
\text { Significantly lower }\end{array}$ \\
\hline 13 & 3.4 & Level of burnout \\
\hline 122 & 31.7 & No symptoms of burnout \\
\hline 214 & 55.6 & Occasionally stressed but not burned out \\
\hline 36 & 9.4 & $\begin{array}{l}\text { Starting to burn out } \\
\text { Consistently feel burned out }\end{array}$ \\
\hline 365 & 95.6 & Completely burned out \\
\hline 381 & 99.7 & Job satisfaction \\
\hline 13 & 3.4 & Very satisfied \\
\hline 31 & 8.1 & Satisfied \\
\hline 2 & 0.5 & $\begin{array}{l}\text { Neither satisfied nor dissatisfied } \\
\text { Dissatisfied }\end{array}$ \\
\hline 149 & 40.5 & Very dissatisfied \\
\hline 150 & 40.8 & Personal and professional balance is right \\
\hline 24 & 6.5 & Strongly agree \\
\hline 28 & 7.6 & Somewhat agree \\
\hline 17 & 4.6 & $\begin{array}{l}\text { Neither agree nor disagree } \\
\text { Somewhat disagree } \\
\text { Strongly disagree }\end{array}$ \\
\hline
\end{tabular}

\begin{tabular}{|c|c|}
\hline $\mathbf{n}^{\mathrm{a}}$ & $\%$ \\
\hline 77 & 21.9 \\
\hline 274 & 78.1 \\
\hline 10 & 13.3 \\
\hline 19 & 25.3 \\
\hline 25 & 33.3 \\
\hline 13 & 17.3 \\
\hline 8 & 10.7 \\
\hline 186 & 50.5 \\
\hline 118 & 32.1 \\
\hline 30 & 8.2 \\
\hline 28 & 7.6 \\
\hline 6 & 1.6 \\
\hline 45 & 12.4 \\
\hline 50 & 13.7 \\
\hline 27 & 7.4 \\
\hline 71 & 19.5 \\
\hline 171 & 47.0 \\
\hline 41 & 11.3 \\
\hline 120 & 33.2 \\
\hline 124 & 34.3 \\
\hline 51 & 14.1 \\
\hline 26 & 7.2 \\
\hline 99 & 27.4 \\
\hline 129 & 35.7 \\
\hline 60 & 16.2 \\
\hline 58 & 16.1 \\
\hline 15 & 4.2 \\
\hline 43 & 11.9 \\
\hline 76 & 21.1 \\
\hline 44 & 12.2 \\
\hline 102 & 28.3 \\
\hline 95 & 26.4 \\
\hline
\end{tabular}

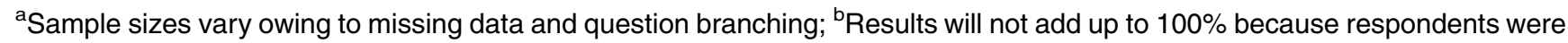
able to check multiple responses. 
Response in \% (n)

\begin{tabular}{|c|c|c|c|c|c|c|c|}
\hline Statements & Mean & SD & Never & Sometimes & the Time & the Time & Always \\
\hline $\begin{array}{l}\text { Social distancing between employees/volun- } \\
\text { teer during break times (maintaining } 6+\mathrm{ft} \text { of } \\
\text { distance) }\end{array}$ & 3.8 & 1.3 & $5.5(17)$ & $16.7(52)$ & 8.7 (27) & $27.7(86)$ & $41.5(129)$ \\
\hline $\begin{array}{l}\text { Social distancing between employees/volun- } \\
\text { teer during meal service (maintaining } 6+\mathrm{ft} \\
\text { of distance) }\end{array}$ & 3.7 & 1.2 & $5.6(19)$ & $18.4(62)$ & $8.6(29)$ & 36.8 (124) & $30.6(103)$ \\
\hline $\begin{array}{l}\text { Social distancing between employees/volun- } \\
\text { teer during meal production (maintaining } 6 \\
+\mathrm{ft} \text { of distance) }\end{array}$ & 3.6 & 1.3 & $7.6(26)$ & $16.0(55)$ & $11.1(38)$ & 36.9 (127) & $28.5(98)$ \\
\hline $\begin{array}{l}\text { No contact meal handoffs with recipients (eg, } \\
\text { placing meals in trunks or back seats rather } \\
\text { than handed to a person) }\end{array}$ & 3.5 & 1.5 & $14.0(46)$ & $18.2(60)$ & 7.0 (23) & $24.9(82)$ & $35.9(118)$ \\
\hline Wearing masks & 2.3 & 1.5 & $46.3(154)$ & $21.0(70)$ & $6.9(23)$ & $12.3(41)$ & $13.5(45)$ \\
\hline
\end{tabular}

emergency meals because they (or someone close to them) were considered part of an at-risk group, their school was shut down, they were sent home, or they felt too unsafe or overstressed to work. Some $(n=6)$ indicated their school/district was not providing meal service during the pandemic primarily because of staff safety concerns.

Most of the respondents (86.6\%) indicated that it was somewhat or much more difficult to ensure employee safety during emergency feeding. The respondents employed various strategies to keep employees safe during the COVID-19 pandemic (Table 2). Social distancing (keeping a distance of $6 \mathrm{ft}$ apart) ${ }^{24}$ between employees/volunteers during break times was the strategy with the greatest percentage of respondents (41.5\%) who reported always practicing it. Almost half (46.3\%) reported never wearing masks at work.

The respondents described their concerns with employee safety during the emergency feeding response through open-ended comments $(\mathrm{n}=315)$ from which 3 themes emerged: exposure and transmission risk, processes, and personal concerns (Table 3). The respondents could contribute to more than 1 theme. The first theme was the fear or risk of exposure and/or transmission of coronavirus. This concern was elevated with descriptions of a lack of personal protective equipment (PPE) at school nutrition sites. One professional wrote, "Food is being transported in workers' vehicles, and vehicles are not being sanitized properly. Unless a worker brings their own sanitizing wipes or hand sanitizer, there is none provided. No masks as of yet, but we will have next week!" (nutrition program staff member, Maine). Others were concerned that either the community or other professionals were not following the recommended prevention guidelines, which could result in increased risk of exposure or transmission. One professional commented,

Staff is not used to social distancing and mitigation measures. This poses an issue when they're not being observed. It is my fear that if one person gets sick, they all will be sick. (nutrition program supervisor, North Carolina)

Another theme that emerged was concern with the processes including the administrative interactions, logistics, and protocols for serving emergency meals. For some, there was a feeling of distrust or lack of support from authority. School districts and state health departments were described as disconnected from the situation, apathetic, or uncaring. "I don't trust that a school nurse understands and/or even cares about whether or not we are safe. They are working from home and have no clue what we are up against," wrote a nutrition program director from Texas. Another expressed concern that "no one seems to care about our safety" (nutrition program staff member, Idaho). Others worried about the limited resources (eg, staff, food, or other items) to meet the new approaches to meal service. One wrote, "We have no B-Team waiting in the wings, and all district staff is primarily already working from home" (nutrition program director, New York). Another cited concern for the funding of the program: "It is costing us considerably more than reimbursements will be" (nutrition program director, Georgia). Finally, within this theme, there were concerns related to the pandemic's disruption of the operation's regular routines and service setups. New practices were described as unsafe or created many contact points for virus transmission. The following comment showed the collective concerns:

It's basically impossible to make the number of meals needed quickly and maintain a 6-feet social distancing policy. The forms USDA requires that we have to have the parents fill out defeats the purpose of the no contact hand-off at the curbside. Without volunteers I wouldn't have the staff to provide the meals but 
Table 3. School Nutrition Professionals' Experience During Coronavirus Disease 2019: Employee Safety Concerns $(n=315)$

\section{Theme}

1. Risk of virus exposure and/or transmission, $n=296$ (94\%)

\section{Processes, $n=113(36 \%)$ Subtheme 1: Support}

Subtheme 2: Resources

\section{Subtheme 3: Production and distribution}
3. Personal concerns, $n=70(22 \%)$ Subtheme 1: High risk, low reward

Subtheme 2: Burnout, frustration, exhaustion

\section{Response}

Even with social distancing protocols on place, worried about contact with each other and contact with public. (nutrition program supervisor, California) We only have masks if we can provide our own. Being in close contact with hundreds of parents puts my own family at risk. (nutrition program manager, Minnesota)

I'm concerned about leaving the house myself and if my staff are practicing social distancing. If not, they are putting all of us at risk. I'm very worried that someone will get sick. (nutrition program director, Wisconsin)

Also, it seems like it will take one of us to get sick before anyone thinks to stop meal service. My girls feel like no one but me cares about their safety because teachers, staff, bus drivers, and all other district employees are expected to stay home. We have been asked to only use nutrition employees, no volunteers outside our department and they will not allow bus driver to deliver because it's too risky. (nutrition program director, Tennessee)

There are no district safety protocols or guidelines. The upper management hasn't taken the time to prepare these plans even when asked. (nutrition program manager, Colorado)

We don't have enough space in the kitchen to socially distance from each other. There are not enough people working. (nutrition program manager, New York)

There are no volunteers, administrators, board members, teachers (noncertified staff) who want to work in food service. I actually only have myself and 2 lunch ladies left. (nutrition program director, Wyoming)

Safe food handling procedures at time of curbside pickup. Some parent/guardian vehicle trunks/hatches are not operable to place meals inside. (nutrition program director, Missouri)

Due to larger amounts of meals being prepared, and workload our kitchen is exposed to more people that are not trained in food service safety protocols, and it is challenging to train a high number of people in such a demanding time. The school is sending in other employees from different departments to assist in the workload, but it increases vulnerability as well with larger amounts of people in and out of our food prep area. (nutrition program manager, Utah)

Some of our employees don't even have health insurance-how will they cover medical need if something happens? They are getting hazard pay, but is it worth it? At what point do we choose feeding the kids over our own health? Feeding is an expectation and when can we call it quits without being blasted by the community? (nutrition program director, Texas)

... most of our staff are in the high-risk category being over the age of 60, yet on the front line... (nutrition program supervisor, Nevada)

Difficult keeping morale up when most other staff in the district can work from home. Staff allowed to volunteer whether to come in or not making some days more difficult to prep with staff available (nutrition program director, Ohio)

We are frightened, overworked, and frustrated. (nutrition program manager, Georgia) having different volunteers every few days is scary. (nutrition program director, Arkansas)

The third employee safety theme included comments addressing personal concerns. Respondents described feelings of exhaustion, fear, and stress. Personal concerns were often rooted in the perspective that working through the pandemic was a high-risk, low-reward situation. One professional expressed frustration with the low pay that many school nutrition professionals receive by writing, "It is frustrating that once again, the lowest paid people in the school district are on the front lines putting themselves at risk to serve the children of our community" (nutrition program director, New Mexico). Others were concerned for themselves, their families, peers, or employees because of the risk factors 
associated with severe illness. One respondent said, "I have a new baby and an immunocompromised son, but I feel I have no choice" (nutrition program staff member, Oklahoma). The respondents also commented on feelings of burnout and frustration. One wrote, "I feel as if I'm all alone but expected to do it all" (nutrition program director, Illinois). Other K12th grade professionals were able to take a break, but the school meal system could not continue functioning if school nutrition professionals chose not to work. One nutrition program staff member felt that current work was, "physically harder and more stressful than a normal day" (nutrition program staff member, Utah).

Finally, the respondents were asked to report their level of burnout, personal/professional balance, and job satisfaction (Table 1). Approximately one third $(34.3 \%)$ indicated that they were experiencing 1 or more symptoms of burnout. Most respondents indicated that they were experiencing some disruption in the balance between their personal and professional lives $(54.7 \%)$. Finally, most respondents were satisfied or very satisfied with their current job (63.1\%).

\section{DISCUSSION}

Overwhelmingly, the respondents indicated it was more difficult to keep school nutrition employees safe during the pandemic. In this study, only one quarter of the respondents indicated wearing a face mask most of the time or always. For context, this is likely to have changed since March/April with more state/community mask mandates and the call by the Centers for Disease Control and Prevention for all Americans to wear a mask on July $14,2020 .{ }^{25}$ As schools are reopening, school nutrition programs may provide masks to their employees and staff training to ensure that child nutrition professionals and students are safe. As school nutrition leaders develop and refine disaster plans, more attention is needed to ensure that school nutrition employees are prepared to act in the role of an essential worker and have necessary PPE. In a 2010 study of essential workers (not including school nutrition employees), $62 \%$ reported having access to respiratory protection (N95 masks, surgical masks, etc). ${ }^{26}$ As schools reopen their campuses over the next year(s), it is important for leaders to review emerging scientific evidence supporting the use of various forms of PPE and other mitigation practices as they develop policies that will keep school nutrition employees safe. This is especially important because essential employees are more likely to be able/willing to work when they feel they have appropriate protection. Providing PPE to employees may help maintain adequate staffing, which is important because without enough school nutrition professionals, many children would become or continue being food insecure during the COVID-19 pandemic.

As K-12 schools are reopening with new service styles and locations of consumption (eg, classrooms, gymnasiums, outdoor areas, etc), it is important to recognize that approximately $40 \%$ of the respondents reported no contact handoffs were only occurring half the time, sometimes, or never in the early phase of the pandemic. In addition, only approximately two thirds of respondents reported they could social distance during breaks, meal service, and production either most of the time or always. Managers and supervisors who create employee work schedules may consider adjusting or staggering normal routines for meal preparation/ production and employee breaks to help make social distancing the default during those activities. For all processes, the safest option needs to be practical enough for employees to comply with as they manage their workloads and interact with students. This will not only keep employees safe but will help school nutrition programs remain sufficiently staffed to protect the children they serve from food insecurity and hunger that could lead to reduced immune response and developmental/psychological harm. ${ }^{27}$

The themes that emerged from the open-ended data revealed how school nutrition professionals felt about their safety while working during the pandemic. More than $90 \%$ of those who responded to the open- ended item highlighted their concern about the risk of virus exposure and/or transmission while at work. This concern aligns with findings from a 2010 survey of essential workers in New York $(n=1,103)$ who indicated they were concerned about being exposed to a potential pandemic influenza at work (74\%), in the community (70\%), and at home $(53 \%) .{ }^{26}$ School nutrition professionals expressed safety concerns owing to a lack of PPE (despite high community exposure) and the difficulty of maintaining social distancing practice among staff, volunteers, and recipients. The comments highlighted concern that some school nutrition staff with chronic health conditions or without health insurance are especially vulnerable in this situation. In the 2010 New York essential workers study $51 \%$ of the workers reported that they would not be able or willing to work for their usual shifts during a pandemic. ${ }^{26} \mathrm{~A}$ low level of concern for infection risk was positively associated with employees' willingness and ability to work. Data from the present study show that despite the sudden transition to essential employee status, many school nutrition professionals are still working even though there are perceived risks (all but 10 respondents reported working during the pandemic). The pandemic presented serious personal and safety implications for school nutrition professionals.

Despite concerns for safety, inadequate resources, and many other challenges, school nutrition professionals have maintained a positive outlook. Even with most respondents not feeling adequate professional/ personal life balance and most feeling at least 1 symptom of burnout, most were extremely satisfied with the meal service they have been able to provide and were satisfied with their current jobs. With the extension of emergency meal waivers until June 30, 2021, that will help reduce food insecurity among children during the continuing pandemic, ${ }^{28}$ school nutrition professionals are still responding creatively to change, doing more than their typical prepandemic routine, and assuming the health risks associated with COVID19. As schools are reopening and 
waiver extensions expire, it is important to recognize the added responsibility school nutrition professionals have borne that has allowed continued feeding during the COVID-19 pandemic.

This study had limitations. There was heterogeneity in school nutrition services across states, urbanicity, and impact of COVID-19 on communities, thus these results may not be generalizable owing to the sampling method used for this study. The cross-sectional design of this study captured the experience of respondents at approximately 1-4 weeks into emergency feeding (95.6\%), which was both a strength and a weakness.

\section{IMPLICATIONS FOR RESEARCH AND PRACTICE}

Understanding the unexpected experiences and challenges of emergency feeding during the COVID-19 pandemic could help administrators and government officials create appropriate resources and guidelines as the current pandemic evolves in the US and as they prepare for other future emergency situations. In addition, information from this study could also be used to help school nutrition professionals understand the employee experience as they create emergency plans for future infectious disease outbreaks as recommended by the Centers for Disease Control and Prevention. ${ }^{29}$ Most schools have a written emergency plan, but less than half have plans for biological events, $^{13}$ such as COVID-19. Few respondents in this study knew if their program had an emergency plan, and the perceived effectiveness broadly varied. Because this study captured the experience of respondents at approximately 1-4 weeks into emergency feeding, other research may explore how the experience changes over time for school nutrition professionals as the pandemic and the US' response evolves. In addition, the researchers could not probe further about the stated experiences because of the methodology; future research could include interviews or focus groups to learn more about the lived experience of these professionals responding to the COVID-19 pandemic. The experiences with COVID19 have demonstrated that a pandemic is a unique emergency with its own challenges. These data support that emergency plans can be improved to include strategies to better protect school nutrition professionals and provide adequate PPE. Increasing preparedness for future biological events will ideally allow school nutrition professionals to minimize child food insecurity while experiencing fewer obstacles than they have with COVID-19.

\section{ACKNOWLEDGMENTS}

The authors thank the Institute of Child Nutrition for sharing this survey link with social media followers.

\section{REFERENCES}

1. US Department of Agriculture, Food and Nutrition Service. Child nutrition tables. https://www.fns.usda.gov/pd/ child-nutrition-tables. Accessed June 11, 2020.

2. US Department of Agriculture, Food and Nutrition Service. Child nutrition programs. https://www.fns.usda.gov/ cn. Accessed June 11, 2020.

3. Ralston K, Treen K, Coleman-Jensen A, Guthrie J. Children's Food Security and USDA Child Nutrition Programs. Washington, DC: US Department of Agriculture; 2017. https://www.ers. usda.gov/webdocs/publications/ 84003/eib-174.pdf?v=3763.2. Accessed June 11, 2020.

4. Centers for Disease Control and Prevention. Coronavirus (COVID-19). https://www.cdc.gov/ coronavirus/ 2019-ncov/index.html. Accessed June 11, 2020.

5. Bayham J, Fenichel EP. Impact of school closures for COVID-19 on the US health-care workforce and net mortality: a modelling study. Lancet Public Health. 2020;5:e271-e278.

6. US Bureau of Labor Statistics. Employment situation summary. https://www. bls.gov/news.release/empsit.nr0.htm. Accessed May 18, 2020.

7. America Feeding. The Impact of the Coronavirus on Child Food Insecurity. Chicago, IL: Feeding America; 2020. https://www.feedingamerica.org/sites/ default/files/2020-04/Brief_Impact $\% 20$ of $\% 20$ Covid $\% 20$ on $\% 20$ Child $\% 20$
Food\%20Insecurity\%204.22.20.pdf. Accessed May 18, 2020.

8. US Department of Agriculture. COVID-19 congregate meal waivers \& Q\&As on summer meal delivery using existing authority. https://www. fns.usda.gov/sfsp/covid-19/ covid19-meal-delivery. Accessed May 18, 2020.

9. American Enterprise Institute. School district responses to the COVID-19 pandemic: round 1 , districts' initial responses. https://www.aei.org/researchproducts/report/school-district-responses-to-the-covid-19-pandemicround-1-districts-initial-responses/. Accessed September 9, 2020.

10. School Nutrition Association. USDA responds quickly in states hit by hurricane, flooding. https://schoolnutrition. org/news-publications/news/2017/ usda-responds-quickly-in-tates-hit-byhurricane-flooding/. Accessed June 11, 2020.

11. School Nutrition Association. Extras from "Weathering the Storm." https:// schoolnutrition.org/news-publications/sn-magazine/bwc/2018/extrasfrom-weathering-the-storm/. Accessed June 16, 2020.

12. US Food and Drug Administration. Food safety and the coronavirus disease 2019 (COVID-19). https://www.fda. gov/food/food-safety-during-emergencies/food-safety-and-coronavirusdisease-2019-covid-19. Accessed May 18,2020

13. Rebmann T, Elliott MB, Artman D, VanNatta M, Wakefield M. Missouri K-12 school disaster and biological event preparedness and seasonal influenza vaccination among school nurses. Am J Infect Control. 2015;43:10281034.

14. School Nutrition Association. Stay at home orders. https://schoolnutrition. org/covid19/stay-at-home-orders/. Accessed September 9, 2020.

15. The Lancet. The plight of essential workers during the COVID-19 pandemic. Lancet. 2020;395:1587.

16. Boin A, Kuipers S, Overdijk W. Leadership in times of crisis: a framework for assessment. Int Rev Public Admin. 2013;18:79-91.

17. Begley TM, Czajka JM. Panel analysis of the moderating effects of commitment on job satisfaction, intent to quit, and health following organizational change. J Appl Psychol. 1993;78:552556. 
18. Starmer AJ, Frintner MP, Freed GL. Work-life balance, burnout, and satisfaction of early career pediatricians. Pediatrics. 2016;137:e20153183.

19. The University of Melbourne. Medicine in Australia: Balancing Employment and Life. https://mabel.org.au/. Accessed June 22, 2020.

20. Dolan ED, Mohr D, Lempa M, et al. Using a single item to measure burnout in primary care staff: a psychometric evaluation. $J$ Gen Intern Med. 2015;30:582-587.

21. Nelson LM, Simard JF, Oluyomi A, et al. US public concerns about the COVID-19 pandemic from results of a survey given via social media. JAMA Intern Med. 2020;180:10201022.

22. Ali SH, Foreman J, Capasso A, Jones AM, Tozan Y, DiClemente RJ. Social media as a recruitment platform for a nationwide online survey of COVID-
19 knowledge, beliefs, and practices in the United States: methodology and feasibility analysis. BMC Med Res Methodol. 2020;20:116.

23. Bogdan R, Biklen SK. Qualitative Research for Education. Boston, MA: Allyn \& Bacon; 1997.

24. Centers for Disease Control and Prevention. How to protect yourself \& others. https://www.cdc.gov/coronavirus/2019-ncov/prevent-getting-sick/ prevention.html?CDC_AA_ref$\mathrm{Val}=\mathrm{https} \% 3 \mathrm{~A} \% 2 \mathrm{~F} \% 2 \mathrm{Fwww} . \mathrm{cdc}$. gov \%2 Fcoronavirus\%2 F2019ncov\%2Fprepare\%2Fprevention.html. Accessed September 9, 2020.

25. Centers for Disease Control and Prevention. CDC calls on Americans to wear masks to prevent COVID-19 spread. https://www.cdc.gov/media/ releases/2020/p0714-americans-towear-masks.html. Accessed September 9, 2020.
26. Gershon RRM, Magda LA, Qureshi KA, et al. Factors associated with the ability and willingness of essential workers to report to duty during a pandemic. J Occup Environ Med. 2010;52:995-1003.

27. Dunn CG, Kenney E, Fleischhacker SE, Bleich SN. Feeding low-income children during the Covid-19 pandemic. N Engl J Med. 2020;382:e40.

28. US Department of Agriculture. Trump administration extends free meals for kids for entire school year. https:// www.usda.gov/media/press-releases/ 2020/10/09/trump-administration-extends-free-meals-kids-entire-schoolyear. Accessed October 28, 2020.

29. Centers for Disease Control and Prevention. Coronavirus disease 2019 (COVID-19). FAQs for administrators, teachers, and parents. https://www. cdc.gov/coronavirus/2019-ncov/community/schools-childcare/schools-faq. html. Accessed May 18, 2020.

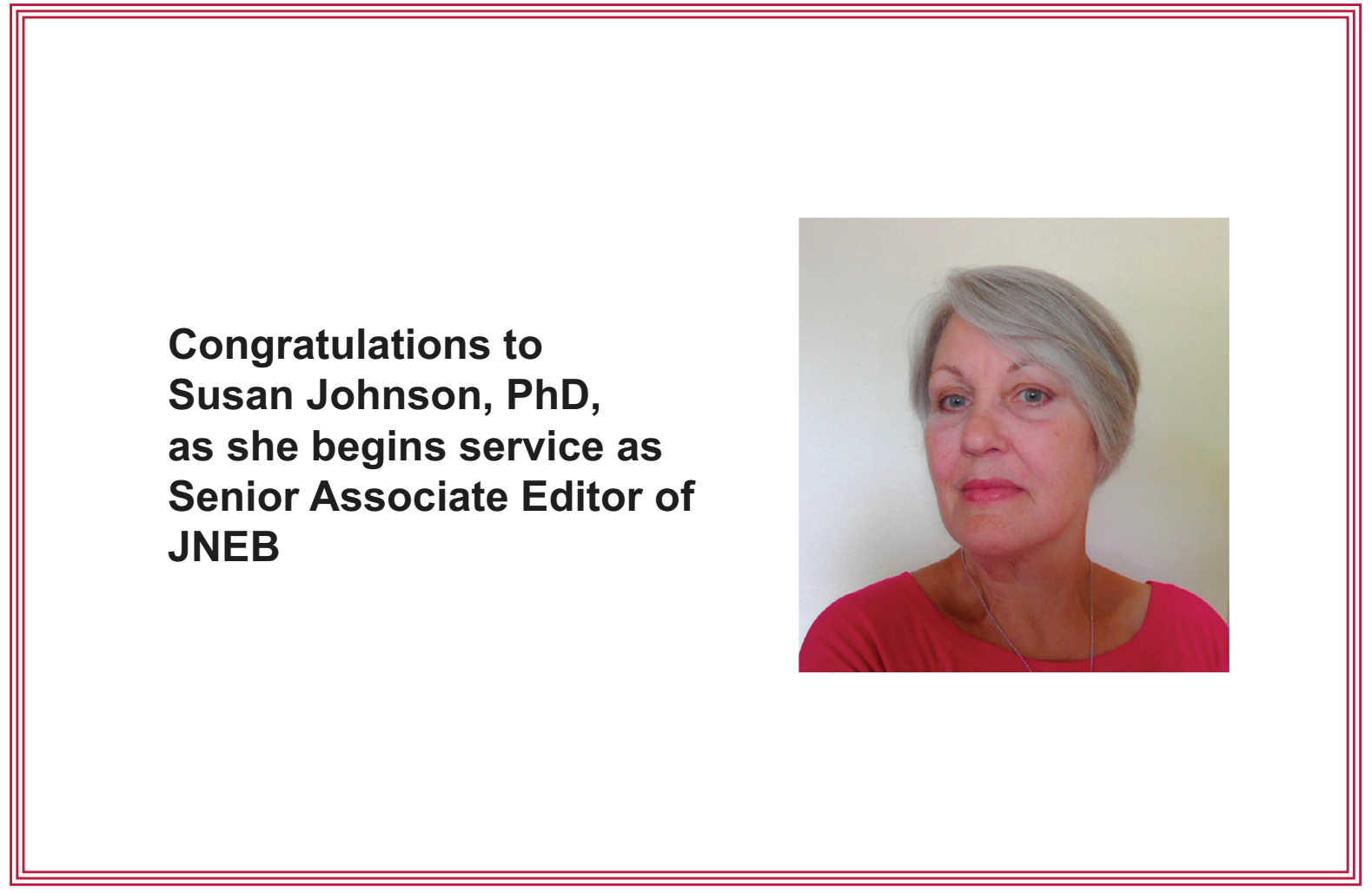

